Case Report

\title{
Chronic Nocturnal Abdominal Pain as the Presentation of Inverted Meckel Diverticulum: A Case Report
}

\author{
Ting-Yu Wang ${ }^{1,2}$, Yu-Tsun Su ${ }^{1,3}$, Po-Jui Ko ${ }^{4}$, Yea-Ling Chen ${ }^{1,3}$, Hsiang-Hung Shih ${ }^{5}$ and Ching-Chung Tsai ${ }^{1,3, *}$ \\ 1 Department of Pediatrics, E-Da Hospital, Kaohsiung City 824005, Taiwan; stopright@gmail.com (T.-Y.W.); \\ suyutsun@yahoo.com.tw (Y.-T.S.); amystella2001@yahoo.com.tw (Y.-L.C.) \\ 2 Department of Pediatrics, U-Sheng Hospital, Pingtung City 900023, Taiwan \\ 3 School of Medicine, I-Shou University, Kaohsiung City 824005, Taiwan \\ 4 Department of Pediatric Surgery, E-Da Hospital, Kaohsiung City 824005, Taiwan; ed106790@edah.org.tw \\ 5 Department of Pediatrics, Kaohsiung Medical University Hospital, Kaohsiung City 807387, Taiwan; \\ 1040561@gap.kmu.edu.tw \\ * Correspondence: u101130@gmail.com; Tel.: +886-7-6150011 (ext. 251295); Fax: +886-7-6150950
}

Citation: Wang, T.-Y.; Su, Y.-T.; Ko, P.-J.; Chen, Y.-L.; Shih, H.-H.; Tsai, C.-C. Chronic Nocturnal Abdominal Pain as the Presentation of Inverted Meckel Diverticulum: A Case Report. Children 2022, 9, 69. https://doi.org/ 10.3390/children9010069

Academic Editor: Richard Lichenstein

Received: 7 December 2021 Accepted: 18 December 2021 Published: 5 January 2022

Publisher's Note: MDPI stays neutral with regard to jurisdictional claims in published maps and institutional affiliations.

Copyright: (C) 2022 by the authors. Licensee MDPI, Basel, Switzerland. This article is an open access article distributed under the terms and conditions of the Creative Commons Attribution (CC BY) license (https:// creativecommons.org/licenses/by/ $4.0 /)$.

\begin{abstract}
The common clinical manifestations of Meckel's diverticulum include painless lower gastrointestinal bleeding and intestinal obstruction due to intussusception. Intussusception induced by inverted Meckel's diverticulum has rarely been reported; furthermore, there is no report thus far of chronic nocturnal abdominal pain as a presenting symptom in children with Meckel's diverticulum. A 4-year-and-10-month-old girl with no significant history of previous illness presented with the sole complaint of chronic nocturnal abdominal pain for 3 months. The patient was reported to be asymptomatic during the day. A provisional diagnosis of chronic ileoileal intussusception was already under consideration in her previous hospital visits elsewhere. Physical examination revealed a soft, non-distended abdomen without tenderness. Imaging studies revealed ileoileal intussusception. Exploratory laparotomy showed ileoileal intussusception induced by an inverted Meckel's diverticulum with ulceration. The patient underwent successful surgery and made a full recovery. We report this case to remind physicians that Meckel's diverticulum should be considered in differential diagnosis of children presenting with the isolated symptom of chronic nocturnal abdominal pain.
\end{abstract}

Keywords: inverted Meckel's diverticulum; intussusception; nocturnal abdominal pain

\section{Introduction}

Meckel's diverticulum is a remnant of the omphalomesenteric duct in the human embryo. There is a "rule of twos" to describe the features of Meckel's diverticulum. It occurs in approximately $2 \%$ of the general population. A Meckel's diverticulum is nearly 2 inches $(5 \mathrm{~cm}$ ) long, usually within 2 feet (approximately $60 \mathrm{~cm}$ ) of the ileocecal valve and located on the antimesenteric border of the ileum. More than $60 \%$ of patients develop symptoms within 2 years of age. In addition, two types of ectopic mucosa can be seen in the diverticulum: gastric and pancreatic. Owing to its location in the right lower quadrant, symptoms are usually similar to those of acute appendicitis when inflamed $[1,2]$.

Intussusception is a common abdominal emergency in children, especially in those younger than two years of age. The typical symptoms and signs of intussusception include intermittent abdominal pain, a palpable abdominal mass in the right upper quadrant, and "currant jelly stool." The etiology of intussusception in children younger than two years of age is idiopathic; however, in those older than 2 years of age, probable lead points such as Meckel's diverticulum, polyps, duplication cyst, or a tumor should be considered [3,4]. We report a case of inverted Meckel's diverticulum presenting with atypical symptom of chronic nocturnal abdominal pain. 


\section{Case Presentation}

A 4-year-and-10-month-old girl with no significant past history of illness presented with chronic nocturnal abdominal pain for 3 months. She always presented in a prone posture with elevated buttocks when having abdominal pain. There were no other associated symptoms such as fever, vomiting, diarrhea, purpura, melena, or rectal bleeding, and she was generally asymptomatic during the day. She was admitted to our hospital with symptoms and findings as described above. Her recent medical history is listed in Table 1.

Table 1. Summary of recent medical history prior to this admission.

\begin{tabular}{ccl}
\hline Date & Hospital & \multicolumn{1}{c}{ Event } \\
\hline $\begin{array}{c}\text { Seven months prior to } \\
\text { this admission }\end{array}$ & A regional hospital & $\begin{array}{l}\text { Intussusception was suspected on } \\
\text { abdominal sonography, and it was } \\
\text { resolved by lower gastrointestinal (LGI) } \\
\text { series reduction }\end{array}$ \\
$\begin{array}{c}\text { Three months prior to } \\
\text { this admission }\end{array}$ & $\begin{array}{l}\text { The same regional } \\
\text { hospital as the 1st } \\
\text { episode }\end{array}$ & $\begin{array}{l}\text { Sonography suspected intussusception } \\
\text { but LGI series revealed no evidence of } \\
\text { intussusception. Incompletely } \\
\text { obstructing intussusception } \\
\text { was suspected. }\end{array}$ \\
\hline $\begin{array}{c}\text { One month prior to } \\
\text { this admission }\end{array}$ & A medical center & $\begin{array}{l}\text { Computed tomography (CT) suspected } \\
\text { intussusception but upper } \\
\text { gastrointestinal series showed negative } \\
\text { finding. Incompletely obstructing } \\
\text { intussusception was suspected again. }\end{array}$ \\
\hline
\end{tabular}

Physical examination revealed a soft, non-distended abdomen without tenderness. Laboratory tests revealed WBC, $142,800 / \mu \mathrm{L}$; neutrophils, $36.3 \%$; eosinophils, $0.8 \%$; lymphocytes, $56.5 \%$; basophils, $1.6 \%$; monocytes, $4.8 \%$; erythrocyte sedimentation rate, $15 \mathrm{~mm} / \mathrm{h}$; aspartate aminotransferase, $22 \mathrm{U} / \mathrm{L}$; alanine aminotransferase, $11 \mathrm{U} / \mathrm{L}$; and creatinine, $0.7 \mathrm{mg} / \mathrm{dL}$. The patient had two CTs (Figure 1), which revealed chronic intussusceptions requiring surgical exploration and exploratory laparotomy showed ileoileal intussusception with markedly dilated proximal small bowel loops without ischemic or necrotic changes (Video S1 in Supplementary Materials). The intussusception was carefully reduced, and a segment of the ileum with a mass was resected. Examination of the resected small bowel revealed a 5-cm-long inverted cord-like structure with ulcerations inside (Figure 2). The pathology report was consistent with an inverted Meckel's diverticulum (Figure 3A,B). The postoperative recovery was smooth and uneventful.
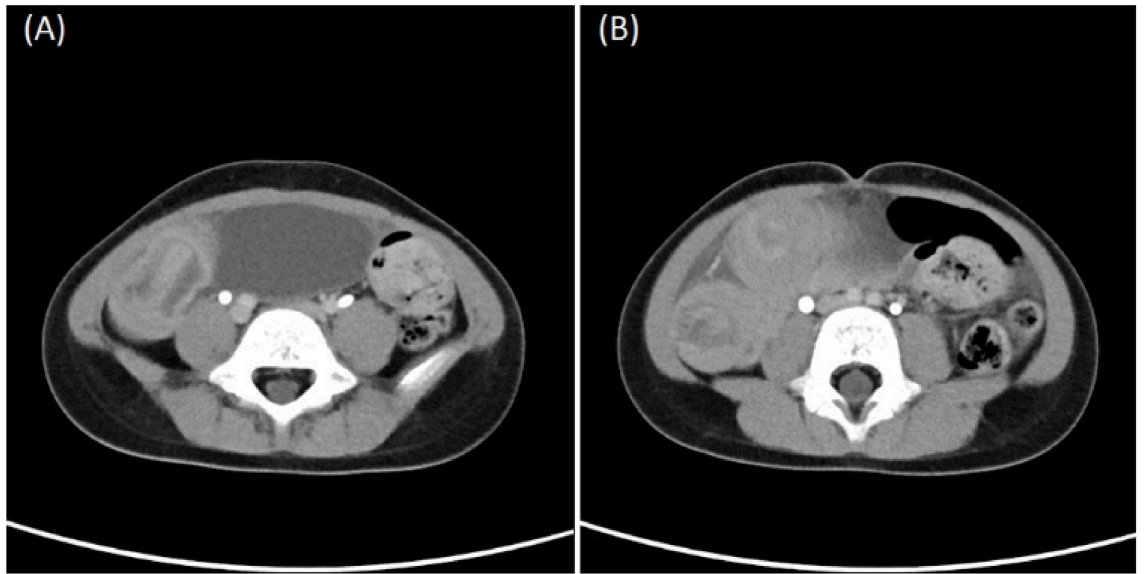

Figure 1. Computed tomography scan (axial view) revealing (A) cord-like structure inside and (B) ileoileal intussusception. 


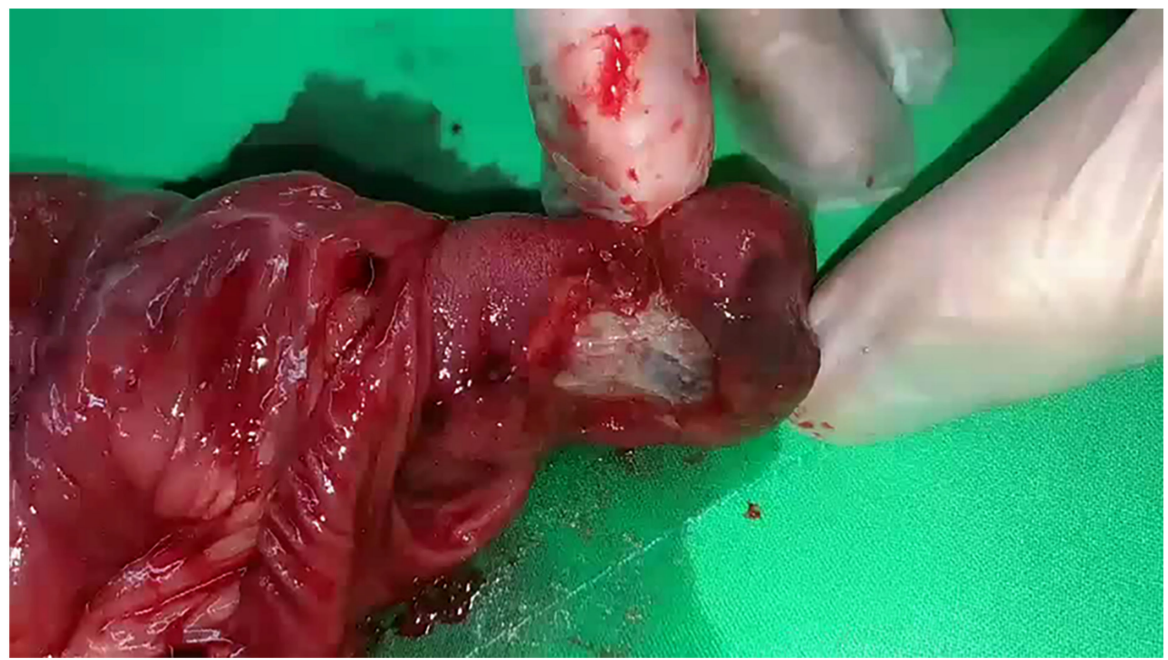

Figure 2. A 5-cm-long inverted cord-like structure with an ulceration is seen upon cutting the resected small bowel open.

(A)

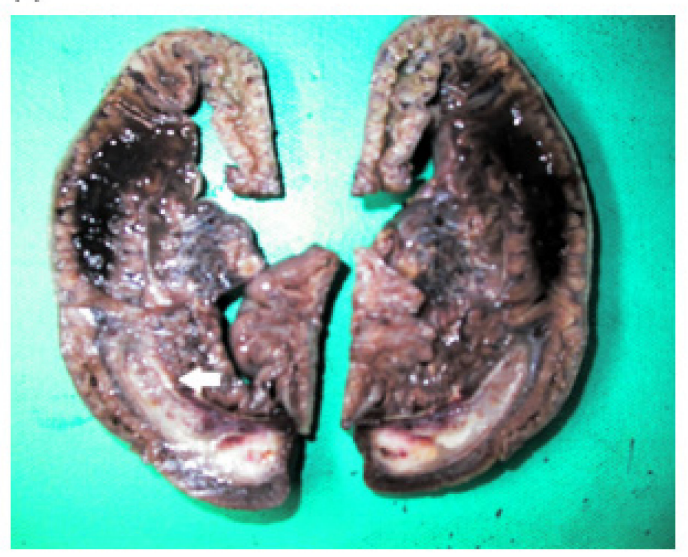

(B)

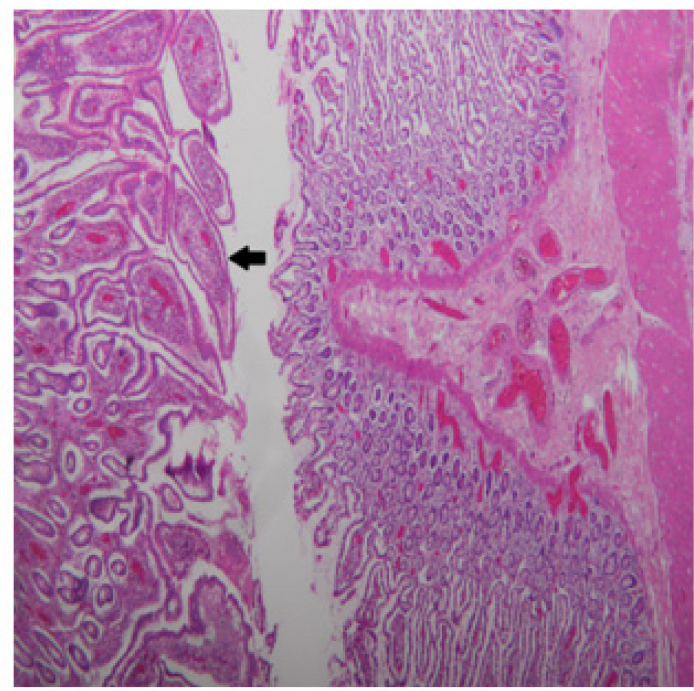

Figure 3. Pathology of resected bowel showing one segment of intestine measuring $15 \mathrm{~cm}$ in length. (A) One segment of rod-like structure $5 \mathrm{~cm}$ in length was observed inside (white arrow), and (B) the segment was lined by the small intestinal epithelium (black arrow). 


\section{Discussion}

The exact mechanism of occurrence of inverted Meckel's diverticulum is poorly understood due to the rarity of this condition. The probable causes of the inversion include abnormal peristalsis around the diverticulum, the diverticulum itself not being fixed, or its inversion due to abnormal peristalsis caused by ulcers or ectopic tissue at the bottom of Meckel's diverticulum [5,6]. Therefore, based on these theories, the inverted Meckel's diverticulum in this case may be secondary to the ulcer on Meckel's diverticulum.

The common clinical manifestations of Meckel's diverticulum include painless brickred LGI bleeding, intestinal obstruction, diverticulitis, and perforation. In Meckel's diverticulum, bleeding is caused by the secretion of acid from the ectopic gastric mucosa, which causes ulcers in the diverticulum or adjacent intestinal mucosa. Consequently, hypovolemic shock due to severe anemia secondary to painless massive bleeding can occur in many children, especially those younger than 2 years of age [7].

The probable reasons for nocturnal abdominal pain alone include the following: (1) chronic incompletely obstructing intussusception, (2) ulcerations on an inverted Meckel's diverticulum without a buffer at night, and (3) it being quieter and easier to concentrate at night without the usual daytime distractions, which magnifies distress and seemingly increases a patient's physical discomfort.

One common clinical manifestation of Meckel's diverticulum is intestinal obstruction related to intussusception, especially in those older than 2 years of age [4]. In this case, successful reduction was achieved following the first medical treatment session, but chronic incompletely obstructing intussusception was suspected on attempted reduction during the second medical treatment session. Perhaps the bowel stiffness that was rendered by the inverted Meckel's diverticulum gradually induced a dilated and looser lumen of the proximal small intestine via chronic intermittent incomplete intussusception. Hence, chronic non-strangulating incompletely obstructing intussusception was likely due to the looser and dilated proximal small intestine. This surmise was proven with observation of the looser and dilated lumen of the proximal small intestine during surgery in this case. Similar painless or painful chronic intussusception induced by lymphoma has also been reported [8,9]. Chronic incompletely obstructing, rather than acute and completely obstructing, intussusception may have been one of contributing factors of chronic intermittent nocturnal abdominal pain. The change in the prone posture and elevation of the buttocks could reduce chronic incompletely obstructing intussusception by the gravity of the intussuseptum.

There are many gastrointestinal diseases associated with abdominal pain at night, such as peptic ulcer, biliary disease, inflammatory bowel disease, irritable bowel syndrome, and gastroesophageal reflux disease (GERD) [10-13]. Nocturnal abdominal pain of peptic ulcer and GERD is associated with the secretion of acid in the empty stomach without any buffer. In addition, peptic ulceration of Meckel's diverticulum or adjacent ileum has been rarely reported to cause pain along with bleeding [14]. In this case, ulcerations on the inverted Meckel's diverticulum without a buffer at night may have been another contributing factor to the chronic intermittent nocturnal abdominal pain.

Clinically, intussusception caused by an inverted Meckel's diverticulum or Meckel's diverticulum in children manifesting as chronic nocturnal abdominal pain alone has rarely been reported. Therefore, we report a case of inverted Meckel's diverticulum presenting with this atypical manifestation instead of typical painless LGI bleeding or intestinal obstruction.

\section{Conclusions}

In conclusion, we report this rare case with atypical clinical manifestations to remind physicians that Meckel's diverticulum should be considered in children presenting with chronic nocturnal abdominal pain alone. 
Supplementary Materials: The following supporting information can be downloaded at: https:/ / www.mdpi.com/article/10.3390/children9010069/s1, Video S1: Intussusception induced by inverted Meckel's diverticulum and manual reduction.

Author Contributions: Y.-L.C., Y.-T.S., T.-Y.W. and C.-C.T. contributed to the literature research. P.-J.K., H.-H.S. and C.-C.T. contributed to providing the relevant images. T.-Y.W., P.-J.K., H.-H.S and C.-C.T. contributed to collecting the clinical data and editing the figures. T.-Y.W. contributed to drafting the manuscript. C.-C.T. contributed to revising the manuscript. All authors have read and agreed to the published version of the manuscript.

Funding: This research received no external funding.

Institutional Review Board Statement: Institutional Review Board in E-Da hospital approved that case report is exempt from formal ethical approval.

Informed Consent Statement: Written informed consent was obtained from the patient's guardian for publication of this case report and accompanying images.

Data Availability Statement: Not applicable.

Conflicts of Interest: The authors declare no conflict of interest.

\section{References}

1. Hansen, C.C.; Søreide, K. Systematic review of epidemiology, presentation, and management of Meckel's diverticulum in the 21st century. Medicine 2018, 97, e12154. [CrossRef] [PubMed]

2. Fu, T.; Xu, X.; Geng, L.; Huang, Y.; Ding, G.; Ji, H. The Clinical Manifestation Variety and Management Choice of Meckel's Diverticulum with Complication: A Single Center Experience. Gastroenterol. Res. Pract. 2021, 2021, 6640660. [CrossRef] [PubMed]

3. Loukas, M.; Pellerin, M.; Kimball, Z.; de la Garza-Jordan, J.; Tubbs, R.S.; Jordan, R. Intussusception: An anatomical perspective with review of the literature. Clin. Anat. 2011, 24, 552-561. [CrossRef] [PubMed]

4. Fiegel, H.; Gfroerer, S.; Rolle, U. Systematic review shows that pathological lead points are important and frequent in intussusception and are not limited to infants. Acta Paediatr. 2016, 105, 1275-1279. [CrossRef] [PubMed]

5. Kim, J.H.; Park, S.H.; Ha, H.K. Case 156: Inverted Meckel diverticulum. Radiology 2010, 255, 303-306. [CrossRef] [PubMed]

6. Bains, L.; Bhatia, R.; Kaushik, R.; Lal, P.; Rajpaul, G. Inverted Meckel's diverticulum: A case report. J. Med. Case Rep. 2021, 15, 264. [CrossRef] [PubMed]

7. Spangler, H.; Fisher, J. The rule of two's didn't work: Meckel's diverticulum with hemorrhagic shock in an adolescent. Am. J. Emerg. Med. 2020, 38, 1541.e1-1541.e2. [CrossRef] [PubMed]

8. Giroux, P.; Collier, A.; Nowicki, M. Recurrent lymphoma presenting as painless, chronic intussusception: A case report. World J. Clin. Cases 2020, 8, 306-312. [CrossRef] [PubMed]

9. Choi, S.H.; Han, S.A.; Won, K.Y. Chronic Intussusception Caused by Diffuse Large B-Cell Lymphoma in a 6-Year-Old Girl Presenting with Abdominal Pain and Constipation for 2 Months. J. Korean Med. Sci. 2016, 31, 321-325. [CrossRef] [PubMed]

10. Kang, J.Y.; Ho, K.Y.; Yeoh, K.G.; Guan, R. Chronic upper abdominal pain due to duodenal ulcer and other structural and functional causes: Its localization and nocturnal occurrence. J. Gastroenterol. Hepatol. 1996, 11, 515-519. [CrossRef] [PubMed]

11. Orfei, M.; Gasparetto, M.; Hensel, K.O.; Zellweger, F.; Heuschkel, R.B.; Zilbauer, M. Guidance on the interpretation of faecal calprotectin levels in children. PLoS ONE 2021, 16, e0246091. [CrossRef] [PubMed]

12. Brandler, J.; Chey, W.D. Fishing for Irritable Bowel Syndrome: Which Alarm Features Weave the Best Net? Clin. Gastroenterol. Hepatol. 2020. [CrossRef] [PubMed]

13. Hunt, R.; Armstrong, D.; Katelaris, P.; Afihene, M.; Bane, A.; Bhatia, S.; Chen, M.H.; Choi, M.G.; Melo, A.C.; Fock, K.M.; et al. World Gastroenterology Organisation Global Guidelines: GERD Global Perspective on Gastroesophageal Reflux Disease. J. Clin. Gastroenterol. 2017, 51, 467-478. [CrossRef] [PubMed]

14. Sheth, R.A.; Gervais, D.A.; Gee, M.A. Imaging of Pediatric Gastrointestinal Disease. In Walker's Pediatric Gastrointestinal Disease: Pathology, Diagnosis, Management, 6th ed.; Kleinman, R.E., Goulet, O.J., Mieli-Vergani, G., Sanderson, I.R., Sherman, P.M., Shneider, B.L., Eds.; PMPH USA, Ltd.: Raleigh, NC, USA, 2018; p. 5443. 